\title{
man \\ NOx-Smoke Trade-off Characteristics in a Palm Oil-Fueled CRDI Diesel Engine under Various Injection Pressures and EGR Rates
}

\author{
Guirong Wu, Jun Cong Ge *, Min Soo Kim * and Nag Jung Choi *(D) \\ Division of Mechanical Design Engineering, Jeonbuk National University, 567 Baekje-daero, Deokjin-gu, \\ Jeonju-si 54896, Korea; wgr@jbnu.ac.kr \\ * Correspondence: jcge@jbnu.ac.kr (J.C.G.); kimms@jbnu.ac.kr (M.S.K.); njchoi@jbnu.ac.kr (N.J.C.)
}

Citation: Wu, G.; Ge, J.C.; Kim, M.S.; Choi, N.J. NOx-Smoke Trade-off Characteristics in a Palm Oil-Fueled CRDI Diesel Engine under Various Injection Pressures and EGR Rates. Appl. Sci. 2022, 12, 1069. https:// doi.org/10.3390/app12031069

Academic Editor:

Georgios Karavalakis

Received: 16 December 2021

Accepted: 19 January 2022

Published: 20 January 2022

Publisher's Note: MDPI stays neutral with regard to jurisdictional claims in published maps and institutional affiliations.

Copyright: (C) 2022 by the authors. Licensee MDPI, Basel, Switzerland. This article is an open access article distributed under the terms and conditions of the Creative Commons Attribution (CC BY) license (https:// creativecommons.org/licenses/by/ $4.0 /)$.

\begin{abstract}
Palm oil is one of the most common and productive vegetable oils, so it is often used as an excellent feedstock for biodiesel production. However, due to the high viscosity and other issues of palm oil, it cannot be directly used as an alternative fuel for diesel engines unless some treatment is carried out. In this study, the effects of palm oil-diesel blend fuel on the nitrogen oxides (NOx)-smoke trade-off characteristics were investigated in a common rail direct injection (CRDI) diesel engine under various injection pressures and exhaust gas recirculation (EGR) rates. It was found that NOx and smoke from the combustion of fuel containing 50\% palm oil (P50D50) were simultaneously suppressed by $3 \%$ and $3.1 \%$ compared with diesel fuel at an injection pressure of 400 bar, respectively. The performance of P50D50 was comparable to that of diesel, but at high injection pressure and high EGR rate, it showed shorter ignition delay (ID) and lower smoke emission.
\end{abstract}

Keywords: injection pressure; NOx; smoke; palm oil; EGR; diesel engine

\section{Introduction}

Diesel engine is one of the main power sources for the transportation industry, but driving vehicles consume a lot of petroleum resources. Transportation has basically become the largest fuel consuming sector in many countries [1]. It is predicted that from 2010, the global transportation energy consumption will increase year by year at a growth rate of $2.2 \%$, and by 2040 , the total consumption will reach 139.5 quadrillion Btu [2], which will continue to exacerbate oil tensions. In addition to the large amount of oil consumption, the pollution problem caused by internal combustion engine (ICE) operation is also becoming very serious, due to emissions of carbon monoxide $(\mathrm{CO})$, hydrocarbons (HC), nitrogen oxides (NOx), and particulate matter (PM) [3]. Researchers are striving to develop new energy vehicle technology, and at the same time emission standards are being tightened to further limit engine pollution. The latest Euro7/VII standards are on the agenda.

In order to solve the increasingly serious oil shortage and environmental problems, the field of ICE technology is constantly evolving. New injection strategies, fuel injection systems, and combustion systems are constantly being developed and used in advanced diesel engines [4]. For example, Blasio et al. combined an advanced Euro VI combustion system and a common rail fuel injection system to successfully develop a dedicated $0.5 \mathrm{dm}^{3}$ single-cylinder engine and found that it has obvious advantages as concerns both smoke and noise emission control [5]. As technology continues to innovate, the search for suitable alternative energy sources has never stopped. For diesel engines, biofuel is one of the most interesting alternative fuels [6], among which biodiesel has attracted the most extensive attention of researchers [7,8]. Biodiesel is usually extracted from various vegetable oils, animal fat, waste cooking oil, and algae by transesterification [9]. Its characteristics are most similar to diesel, and it is the most popular alternative fuel for diesel engines. Although the combustion quality of the engine is improved due to the oxygen contained in biodiesel, 
the high pollution in the production process deserves further reflection [10]. According to estimates, when the diesel engine works at full load, the specific environmental pollution cost and the total environmental pollution cost of biodiesel are higher than those of diesel [11]. Therefore, some scholars have tried to use vegetable oils (i.e., palm oil, soybean oil, rapeseed oil, and sunflower oil) directly as an alternative fuel for diesel [12]. Among them, palm oil is the most important petroleum product, accounting for more than one-third of the world's total output. Palm is a common oil crop with high oil yield, and its oil has good performance in productivity, marketability, and land use [13]. Palm oil is made by pressing palm fruits, which contain a large amount of gelatin and free fatty acids, and is the main raw material of palm oil biodiesel [14]. Similar to other vegetable oils, the substitution of palm oil after simple treatment can reduce the consumption of fossil energy and help improve the ratio of carbon neutrality [15]. Since there is no further processing cost, the cost of palm oil is usually low. However, palm oil contains a large amount of colloid and free fatty acids, which increase the viscosity of palm oil and affect the fluidity and spray state. Therefore, the pure palm oil cannot be directly used in engines [14].

In order to solve the main problem of high viscosity of vegetable oils, researchers usually adopt four methods: direct dilution, microemulsion, pyrolysis, and transesterification $[16,17]$. Crude vegetable oil can be treated simply to meet the requirements of engine operation. Hazar et al. [18] mixed rapeseed oil and diesel in the proportions of $0 \%, 20 \%$, and $50 \%$, respectively, and heated the mixture to $100^{\circ} \mathrm{C}$ in the optimal conditions. It was found that the blends containing rapeseed oil had less emissions, except for NOx, and preheating was more conducive to the improvement of performance. Chauhan et al. [19] discussed the influence of preheating temperature on jatropha oil and pointed out that the viscosity of the oil decreased sharply with the increasing temperature. The combustion of unheated jatropha oil emits higher $\mathrm{CO}$ and $\mathrm{HC}$ amounts than diesel, which can be alleviated only after the oil is preheated. Sankumgon et al. [16] mixed jatropha oil, diesel oil, and ethanol ternary and added a non-ionic surfactant in the control group to improve the mixing effect. It was found that the increase in ethanol and surfactant content reduced the viscosity of the fuel mixture, and $\mathrm{CO}$ and smoke emissions were also greatly reduced. While the problem of high viscosity can be solved in these ways, there are inconveniencies. Although preheating can effectively reduce oil viscosity, components of the engine fuel system are often closely matched, so excessive fuel inlet temperature may adversely affect the fuel system [20]. Transesterification is currently a widely accepted processing method, but the production cost of biodiesel varies greatly due to different processing methods and raw material costs, usually 0.5 to $80 \mathrm{k}$ US dollars/ton [21], of which raw material costs account for the largest proportion. Transesterification process is also a high-cost step. By contrast, direct mixing and diluting with a low-viscosity fuel is a simpler method that requires no chemical process. In addition to diluting vegetable oil with other low-viscosity fuels, a moderate increase in injection pressure can also improve the problem of atomization caused by high viscosity. Increasing the injection pressure can improve the fuel injection distance and atomization area in the cylinder, thus optimizing the quality of the oil-gas mixture.

Although palm oil biodiesel has been widely studied, there is little research on crude palm oil in a in a common rail direct injection (CRDI) diesel engine. Considering that the viscosity of palm oil deteriorates the atomization effect, and the high oxygen content of palm oil also affects the combustion quality, two conditions including to injection pressure and EGR, were respectively introduced to improve the shortcomings of palm oil. This work investigated the effects of different injection pressures (300-450 bar) and EGR rates $(0-20 \%)$ on engine performance, combustion characteristics, and NOx-Smoke trade-off characteristics using palm oil blends.

\section{Experimental Setup and Procedure}

\subsection{Test Fuels}

In order to intuitively reflect the characteristics of palm oil as a fuel, in this work, pure palm oil without transesterification was mixed with commercial diesel at a volume ratio 
of 1:1, which is recorded as P50D50 (50\% palm oil + 50\% diesel). D100 (100\% commercial diesel) was used as a control to observe the effect of palm oil on the properties of the blend. The fuel properties are shown in Table 1.

Table 1. Fuel properties.

\begin{tabular}{ccc}
\hline Properties (Units) & Crude Palm Oil & Diesel \\
\hline Density $\left(\mathrm{kg} / \mathrm{m}^{3}\right.$ at $\left.15^{\circ} \mathrm{C}\right)$ & 903.8 & 836.8 \\
Calorific value $(\mathrm{MJ} / \mathrm{kg})$ & 39.34 & 43.96 \\
Viscosity $\left(\mathrm{mm}^{2} / \mathrm{s}\right.$ at $\left.40^{\circ} \mathrm{C}\right)$ & 42.21 & 2.719 \\
Cetane index & 49 & 55.8 \\
Flash point $\left({ }^{\circ} \mathrm{C}\right)$ & 260 & 55 \\
Oxygen content $(\%)$ & 11.4 & 0 \\
\hline
\end{tabular}

\subsection{Test Engine and Operating Procedure}

The test and data collection in this study were carried out on an engine test system, which is shown in Figure 1. The test engine was a Hyundai in-line four-cylinder CRDI diesel engine whose specifications are shown in Table 2. The engine speed and load were controlled at $1600 \mathrm{rpm}$ and $40 \mathrm{Nm}$, respectively, by an eddy current dynamometer (Hwanwoong Mechatronics Co., Ltd., Gyeongnam, Korea). The relevant combustion pressure was measured by a piezoelectric pressure sensor (Type 6056A, Kistler Korea Co., Ltd., Seongnam-si, Korea) and recorded using a National Instruments PCI-6040E (National Instruments, Austin, TX, USA) data acquisition (DAQ) board. The fuel consumption of the engine was processed from the data obtained from a high-precision digital electronic weighing balance (GP-100K, A\&D Co. Ltd., Tokyo, Japan). The GreenLine MK2 exhaust gas analyzer (Eurotron (Korea) Ltd., Seoul, Korea) and OP160 non-spectrophotometer (EPLUST Co., Ltd., Seongnam-si, Korea) were used for the measurement of NOx and smoke opacity, respectively. The pilot and main injection timings were separately set at 21 CA BTDC and 6 CA BTDC. The main difference between the two test conditions was the presence of EGR. When the EGR valve was closed, the fuel injection pressure was set to 300, 350, 400, and 450 bar in sequence, while when the EGR valve was open, $0 \%, 10 \%, 20 \%$ of EGR was introduced, under the injection pressures of 300 and 450 bar, representing low and high injection pressures. The engine was warmed up at an idling speed until the cooling water temperature stabilized at $85^{\circ} \mathrm{C}$, when a smooth operating condition was reached. The test conditions are reported in Table 3, and the EGR rate involved can be calculated by the following:

$$
\mathrm{EGR} \text { rate }=\frac{V_{1}}{V_{1}+V_{2}}
$$

$V_{1}$ represents the volume of exhaust gas introduced into the cylinder, and $V_{2}$ represents the volume of fresh air entering the cylinder.

Table 2. Engine specifications.

\begin{tabular}{cc}
\hline Parameter (Units) & Specification \\
\hline Engine type & In-line Four-cylinder \\
Air intake system & Turbocharger with WGT \\
Bore $\times$ stroke $(\mathrm{mm})$ & $83 \times 92$ \\
Displacement $(\mathrm{cc})$ & 1991 \\
Compression ratio & $17.7 / 1$ \\
Maximum power $(\mathrm{kW} / \mathrm{rpm})$ & $82 / 4000$ \\
Fuel injection system & 5 \\
Number of injector nozzle holes & 150 \\
Injector spray angle (degree) & 0.17 \\
Injector hole diameter (mm) &
\end{tabular}




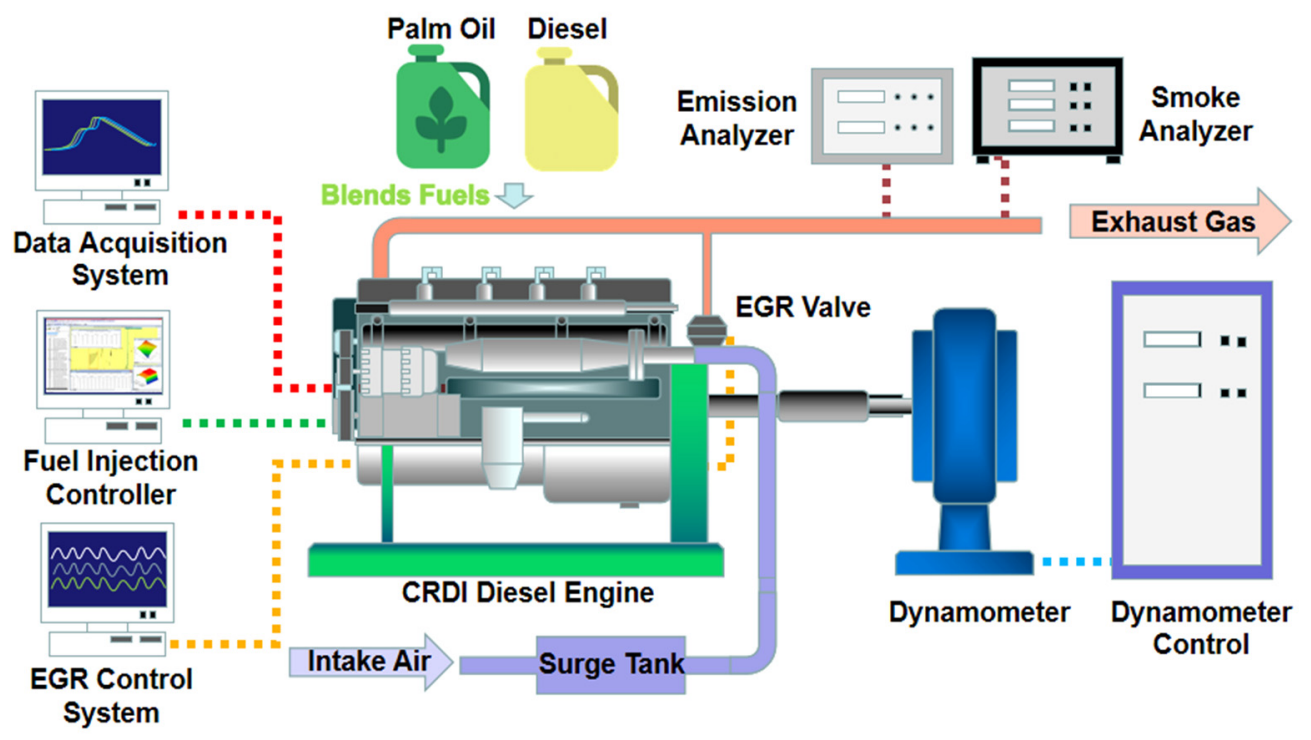

Figure 1. Engine test system.

Table 3. Test and operating conditions.

\begin{tabular}{ccc}
\hline Item (Unit) & Conditions \\
\hline Test fuels & D100, P50D50 \\
EGR rate (\%) & without EGR & $0,10,20$ \\
Injection pressure (bar) & $300,350,400,450$ & 300,450 \\
Speed (rpm) & 1600 & \\
Load (Nm) & 40 & \\
Pilot injection timing $\left({ }^{\circ} \mathrm{CA}\right.$ BTDC) & 21 & \\
Main injection timing $\left({ }^{\circ} \mathrm{CA} \mathrm{BTDC}\right)$ & 6 & \\
Intake air temperature $\left({ }^{\circ} \mathrm{C}\right)$ & $25 \pm 3$ & \\
Cooling water temperature $\left({ }^{\circ} \mathrm{C}\right)$ & $85 \pm 3$ & \\
\hline
\end{tabular}

\subsection{Uncertainty and Error}

The test status and data collection are affected by various factors, such as human operation errors, instrument errors, fluctuations caused by environmental factors, etc. Therefore, each parameter in the test was measured three times, and the average value was taken as the official one in order to obtain more accurate results. The measurement accuracy of the main parameters involved is shown in Table 4.

Table 4. Measurement accuracy of the main parameters.

\begin{tabular}{cc}
\hline Parameter (Units) & Accuracy \\
\hline Fuel injection pressure (bar) & \pm 1 \\
Speed (rpm) & \pm 5 \\
Load (Nm) & $\pm 0.2 \%$ \\
Intake air temperature $\left({ }^{\circ} \mathrm{C}\right)$ & \pm 3 \\
Cooling water temperature $\left({ }^{\circ} \mathrm{C}\right)$ & \pm 3 \\
Fuel consumption $(\mathrm{g})$ & \pm 2 \\
NOx (ppm) & $\pm 0.25 \%$ \\
Smoke opacity $(\%)$ & $\pm 1 \%$ \\
\hline
\end{tabular}

\section{Results and Discussion}

This section is divided by subheadings to provide a concise and precise description of the experimental results, their interpretation, as well as the experimental conclusions that can be drawn. 


\subsection{Effects of Injection Pressure}

\subsubsection{Combustion Characteristics}

Figure 2 reflects the performance of cylinder pressure $(\mathrm{CP})$ and heat release rate (HRR) for different fuels at incremental injection pressures. The peaks of $\mathrm{CP}$ and HRR and their corresponding crank angles are summarized in Table 5. It can be observed for all fuels that the larger injection pressure increased the cylinder pressure peak. Compared with the injection pressure under $300 \mathrm{bar}$, the peak pressure of D100 increased by $5 \%, 8.5 \%$, and $13.5 \%$ at 350,400 , and 450 bar, respectively, while that of P50D50 increased by $3.7 \%, 9.1 \%$, and $12.6 \%$. The trend of HRR was similar to that of $\mathrm{CP}$, which HRRmax increased with the injection pressure. From the data in Figure 2 and Table 5, it can be seen that before reaching the peak, the injection pressure positively affected the rise rate of HRR, advanced the heat release of the fuel, and shortened the period required to reach the maximum value of HRR. This may be attributed to the fact that the fuel in the injector achieved higher kinetic energy under high pressure, thereby forming droplets with smaller diameters, which improved the fuel distribution in the cylinder [22]. A better atomization of the fuel is conducive to better mixing of the mixed gas in the pre-mixing stage and to a more adequate and earlier release of the heat contained, which is reflected in the higher CP and HRR [23,24]. For different fuels, it can be found that the CPmax of D100 was always greater than that of P50D50. In addition to poor spray atomization due to the larger viscosity and density of P50D50, the large heating value of D100 was the key to a larger CP. In a word, the peak values of CP and HRR increased due to a higher premixed combustion phase resulting from a better atomization of the fuel at higher injection pressure.

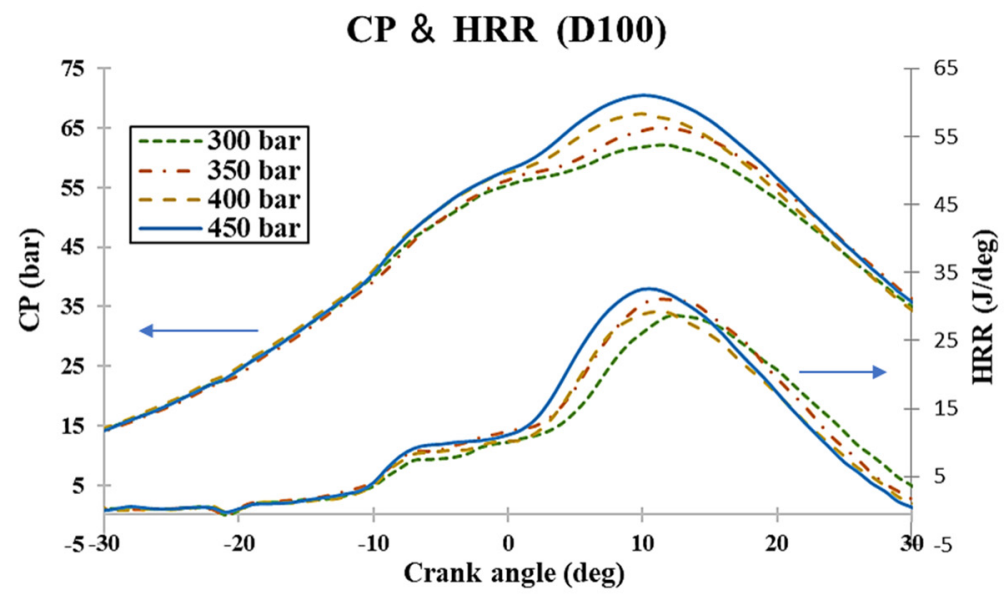

CP \& HRR (P50D50)

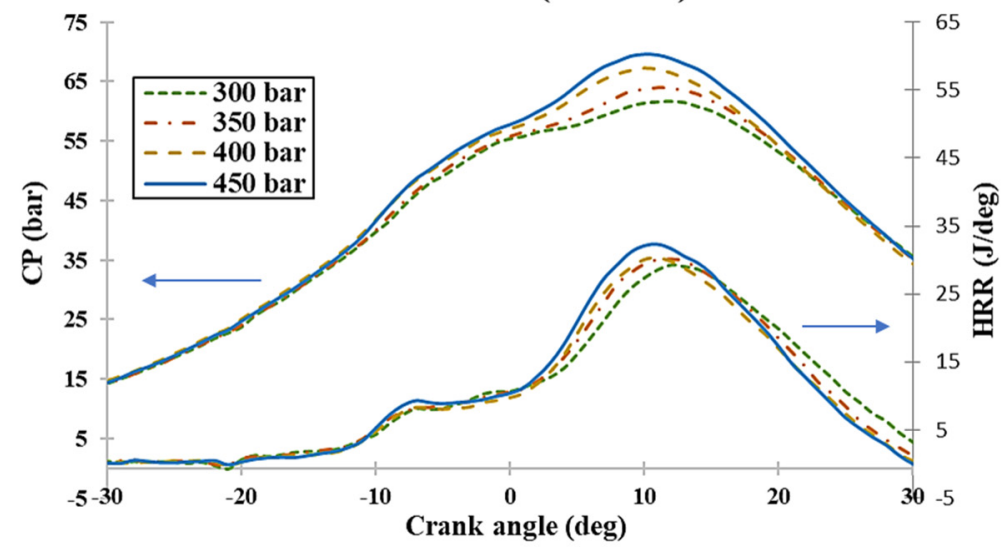

Figure 2. $\mathrm{CP}$ and HRR variations under various injection pressures. 
Table 5. Maximum values of $\mathrm{CP}$ and HRR and their corresponding crank angles (without EGR).

\begin{tabular}{|c|c|c|c|c|c|}
\hline Fuel & Injection Pressure (bar) & CPmax (bar) & $\begin{array}{c}\text { CPmax Crank Angle } \\
\left({ }^{\circ} \mathrm{CA}\right)\end{array}$ & HRRmax (J/deg) & $\begin{array}{c}\text { HRRmax Crank } \\
\left.\text { Angle ( }{ }^{\circ} \mathrm{CA}\right)\end{array}$ \\
\hline \multirow{4}{*}{ D100 } & 300 & 62 & 12 & 28.57 & 12 \\
\hline & 350 & 65.1 & 11 & 31.00 & 11 \\
\hline & 400 & 67.3 & 10 & 30.56 & 11 \\
\hline & 450 & 70.4 & 10 & 33.16 & 10 \\
\hline \multirow{4}{*}{ P50D50 } & 300 & 61.7 & 12 & 29.28 & 12 \\
\hline & 350 & 64 & 11 & 30.21 & 12 \\
\hline & 400 & 67.3 & 10 & 30.39 & 11 \\
\hline & 450 & 69.5 & 10 & 32.24 & 11 \\
\hline
\end{tabular}

Ignition delay (ID) is mostly defined as the crank angle corresponding to the start of fuel injection to $10 \%$ of the combustion mass, which varies with injection pressure and fuel properties. As shown in Figure 3, a high injection pressure significantly shortened the ID. When the injection pressure varied from 300 bar to 400 bar, the ID was greatly shortened. When the injection pressure reached $450 \mathrm{bar}$, the ID was the shortest, especially for P50D50, whose ID was shortened by 33\%. A high injection pressure often leads to spray droplet diameter, shorter split length, and wider dispersion, which minimizes local fuel accumulation [25]. Good atomization makes a mixture more uniform, thus reducing the ID [26]. A shorter ID means that the heat release starts earlier, which is consistent with the previous statement that the heat release of fuel advances with the increase in injection pressure. The ID of P50D50 was longer than that of D100 under the same conditions, which may be attributed to the fact that crude palm oil reduced the cetane number of the blend. A high injection pressure is conducive to a shorter ID.



Figure 3. ID under various injection pressures.

\subsubsection{Engine Performance}

Figure 4 shows the variation of the brake-specific fuel consumption (BSFC) with different fuels and injection pressures. The results show that the BSFC of the fuels at the injection pressure of 450 bar was higher than that at 300 bar. It is worth noting that the BSFC of D100 first fell and then rose with the gradual increase of injection pressure. This could be caused by the fact that the large injection pressure created a better atomization atmosphere in the early stages, and the fuel could easily evaporate and mix, which was conducive to better combustion. However, as the injection pressure continued to increase, the spray permeability worsened. The local lack of oxygen and uneven mixing of oil and gas caused by this led to the rise of BSFC [23]. It can also be observed that, due to the difference in fuel 
heating values, the BSFC under the same injection pressure was negatively correlated with the fuel heating value.

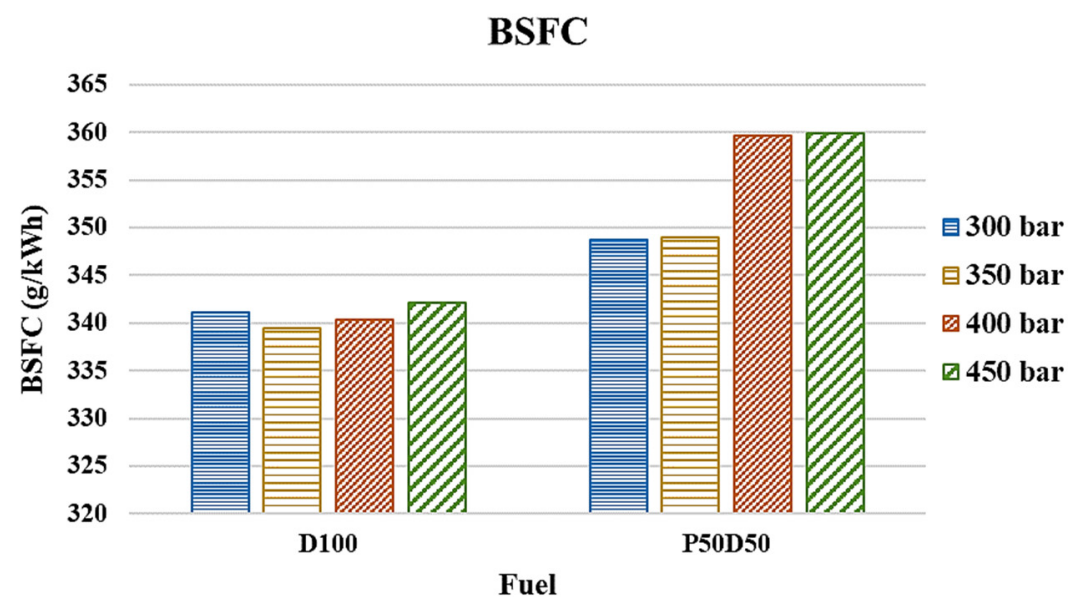

Figure 4. BSFC under various injection pressures.

Brake thermal efficiency (BTE) is the reciprocal of the product of BSFC and the calorific value of the fuel, so the trends of BTE and BSFC are often opposite, as shown in previous studies [27,28]. Figure 5 depicts the BTE of the test fuel under four injection pressures. It can be directly observed that the BTE of the same fuel was negatively correlated with the variation of BSFC. However, interestingly, the fuels with the best BSFC performance did not show the best BTE. Under the same operating conditions, D100 always exhibited the lowest BSFC, but at 350 and 400 bar, P50D50 had the highest efficiency. It can be inferred that, compared to D100, the growing rate in BSFC of P50D50 was slightly lower than the decrease in heating value.

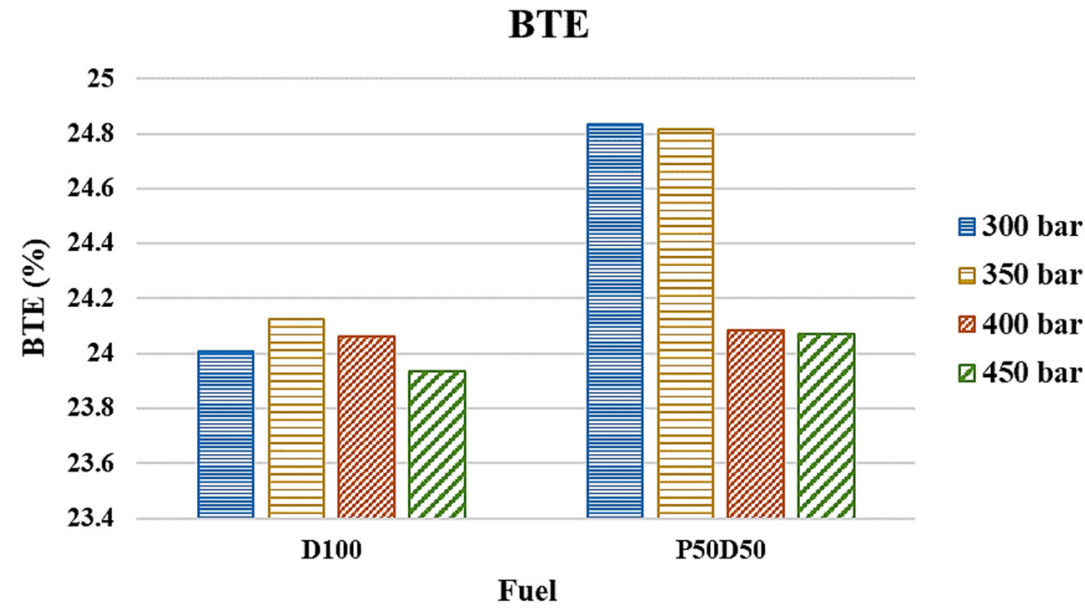

Figure 5. BTE under various injection pressures.

Figure 6 compares the exhaust gas temperature (EGT) of the two test fuels. It can be seen that the EGT of P50D50 was significantly higher than that of D100 at 300 bar. However, when the injection pressure was higher than 300 bar, the EGT of P50D50 was lower than that of D100. This shows that the fuel could not be fully atomized under low injection pressure, and the viscosity of palm oil in the mixed fuel was high, which further worsened the atomization effect and led to incomplete combustion, thus consuming a large amount of fuel and increasing EGT. In general, a lower EGT indicates that the fuel is fully burned and the engine efficiency is high [29]. In this study, a higher injection pressure improved the atomization effect. In addition, palm oil has high oxygen content and high cetane number, 
which promote combustion. Therefore, the addition of palm oil to diesel resulted in lower EGT at high injection pressures.

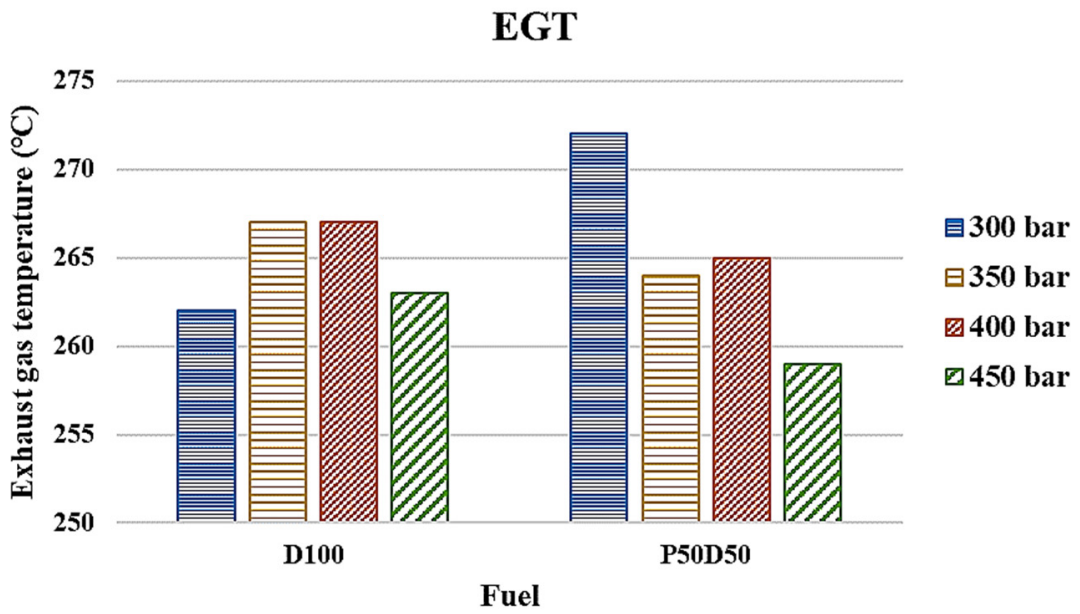

Figure 6. EGT under various injection pressures.

\subsubsection{Emission Characteristics}

A high injection pressure promoted the formation of NOx. As depicted in Figure 7, at the injection pressure of 300 bar, D100 and P50D50 generated 499 and 519 ppm NOx, respectively, which were maintained at a relatively low level. However, when the injection pressure was gradually increased to 450 bar, the emitted NOx also increased to 726 and $735 \mathrm{ppm}$, with a maximum increase rate of $45.5 \%$. The formation of NOx depends on oxygen concentration, peak temperature, and residence time in the cylinder [30]. Although a high injection pressure limits the penetration range of the fuel, it greatly refines the spray particle size, which is conducive to rapid fuel evaporation and heat release, resulting in higher cylinder temperature, thereby promoting the production of NOx [31-33]. Regarding the influence of fuel, D100 released less NOx at 300 and 450 bar injection pressures, but its NOx emission performance was inferior to that measured at medium injection pressure.

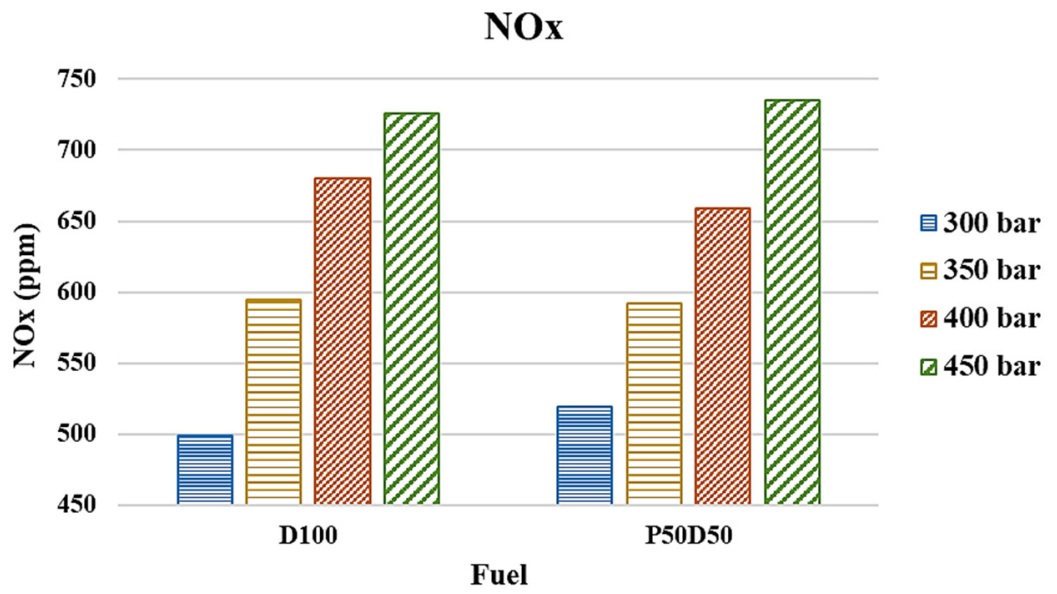

Figure 7. NOx emissions under various injection pressures.

Figure 8 shows the smoke released by the combustion of various fuels under different injection pressures. Contrary to the behavior of NOx, smoke opacity improved as the injection pressure increased. Under lower injection pressures, the atomization condition was not good, and the ejected fuel droplets had a larger diameter, easily becoming the precursor core of particulate matter; however, under higher injection pressures, atomization improved, and the fuel particle size became smaller. The fuel could be easily mixed with air 
and burned better, contributing fewer smoke emissions [23,25,31]. The very high viscosity of palm oil deteriorated the spray performance of P50D50 and caused a larger mist particle diameter, which facilitated the formation of particles. Therefore, the burning of P50D50 released more smoke, and only at 400 bar did it showed less emissions.

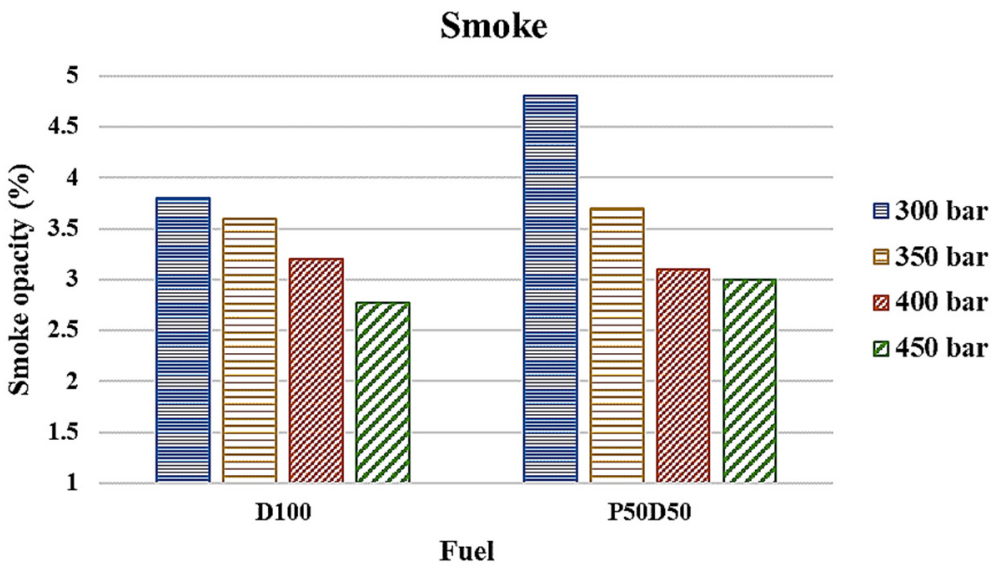

Figure 8. Smoke opacity under various injection pressures.

\subsection{Effects of EGR Rate}

\subsubsection{Combustion Characteristics}

The CP and HRR curves of D100 and P50D50 introducing different EGR rates is shown in Figure 9 and the data are listed in Table 6. Regardless of the injection pressure, the peak $\mathrm{CP}$ and HRR of the fuels decreased regularly with the growth of the EGR rate. When the injection pressure was 300 bar, 10\% and 20\% EGR rate reduced the CPmax of the D100 by $3.1 \%$ and $5.2 \%$, respectively, while at 450 bar, the reduction was of $4.7 \%$ and $5.9 \%$. For P50D50, the drops under the two injection pressures were $3.5 \%$ and $6.1 \%$ and $2.7 \%$ and $4.0 \%$, respectively. The gas reintroduced by the EGR system increased the specific heat of the gas in the cylinder and reduced the oxygen content, which was not conducive to the full combustion of the fuel, thereby reducing the peak pressure [34,35]. It was also found that the EGR weakened the peak pressure of D100, so that P50D50 showed a higher CP after the introduction of EGR. This could be caused by the oxygen contained in palm oil, which increased the oxygen concentration in the cylinder. Furthermore, since the oxygen atoms contained in palm oil could effectively increase the oxygen concentration of the oil-gas mixture, the peak attenuation of P50D50 by EGR was less than that of D100. Therefore, under high injection pressure, P50D50 suffered from a smaller image with a high EGR rate (suffered less from a high EGR rate).

Table 6. Maximum values of CP and HRR and their corresponding crank angles (with EGR).

\begin{tabular}{|c|c|c|c|c|c|c|}
\hline Fuel & $\begin{array}{c}\text { Injection } \\
\text { Pressure (bar) }\end{array}$ & EGR Rate (\%) & CPmax (bar) & $\begin{array}{c}\text { CPmax Crank } \\
\text { Angle (CA) }\end{array}$ & $\begin{array}{c}\text { HRRmax } \\
\text { (J/deg) }\end{array}$ & $\begin{array}{c}\text { HRRmax Crank } \\
\text { Angle (CA) }\end{array}$ \\
\hline \multirow{6}{*}{ D100 } & \multirow{3}{*}{300} & 0 & 62 & 11 & 28.58 & 12 \\
\hline & & 10 & 60.1 & 11 & 27.98 & 12 \\
\hline & & 20 & 58.8 & 11 & 27.41 & 12 \\
\hline & \multirow{3}{*}{450} & 0 & 70.4 & 10 & 32.47 & 10 \\
\hline & & 10 & 67.1 & 10 & 30.86 & 10 \\
\hline & & 20 & 66.3 & 11 & 32.12 & 10 \\
\hline \multirow{6}{*}{ P50D50 } & \multirow{3}{*}{300} & 0 & 61.7 & 12 & 29.28 & 12 \\
\hline & & 10 & 60.2 & 12 & 28.25 & 13 \\
\hline & & 20 & 59 & 12 & 27.49 & 13 \\
\hline & \multirow{3}{*}{450} & 0 & 69.5 & 10 & 32.24 & 11 \\
\hline & & 10 & 67.6 & 11 & 32.66 & 11 \\
\hline & & 20 & 66.7 & 10 & 31.09 & 11 \\
\hline
\end{tabular}




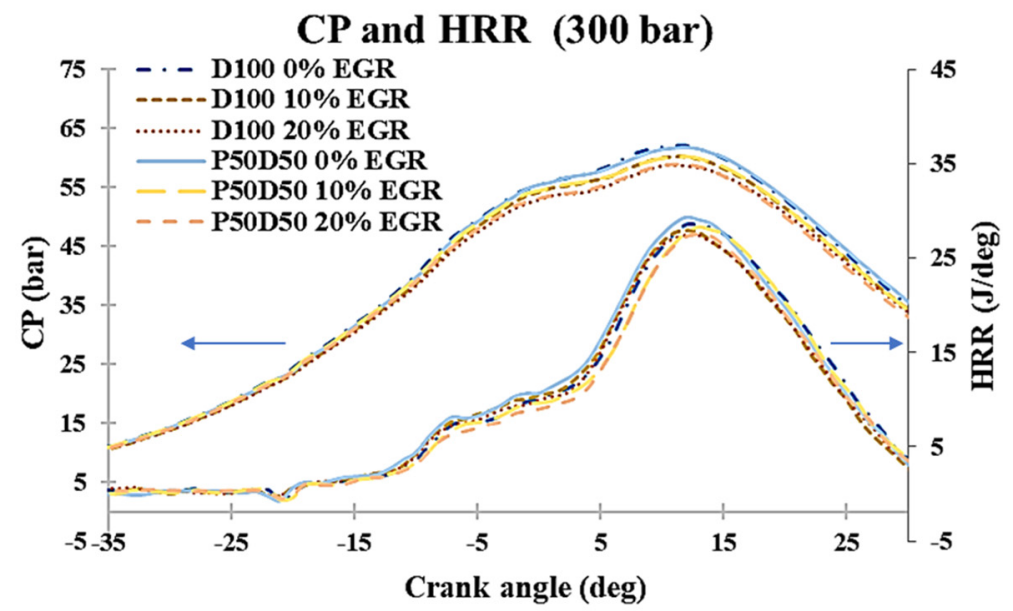

CP and HRR (450 bar)

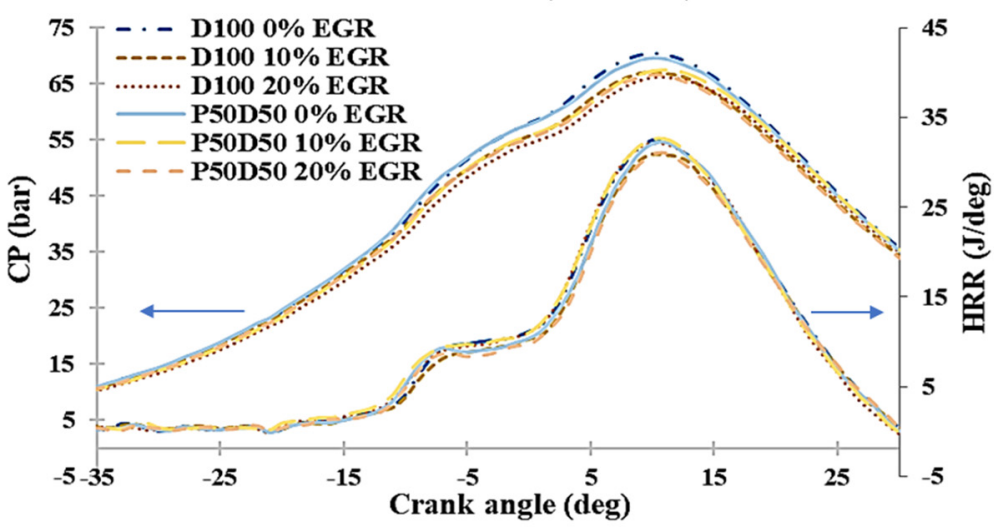

Figure 9. CP and HRR under different EGR rates at 300 and 450 bar.

The influence of EGR on the ID of D100 and P50D50 is shown in Figure 10. The injection pressure in this work was the main factor that affected the ID, and a high injection pressure was conducive to a shorter ID. Because the exhaust gas introduced influenced the pre-oxidation process of the fuel, and the low heat and dilution effect of EGR delayed the progress of the chemical reaction, the ID variation was positively correlated with the EGR rate [36,37]. Moreover, the reduced oxygen concentration in the intake due to EGR was well compensated by the specific oxygen in palm oil, which resulted in a lower ID for P50D50 than for D100 at all EGR rates.

ID

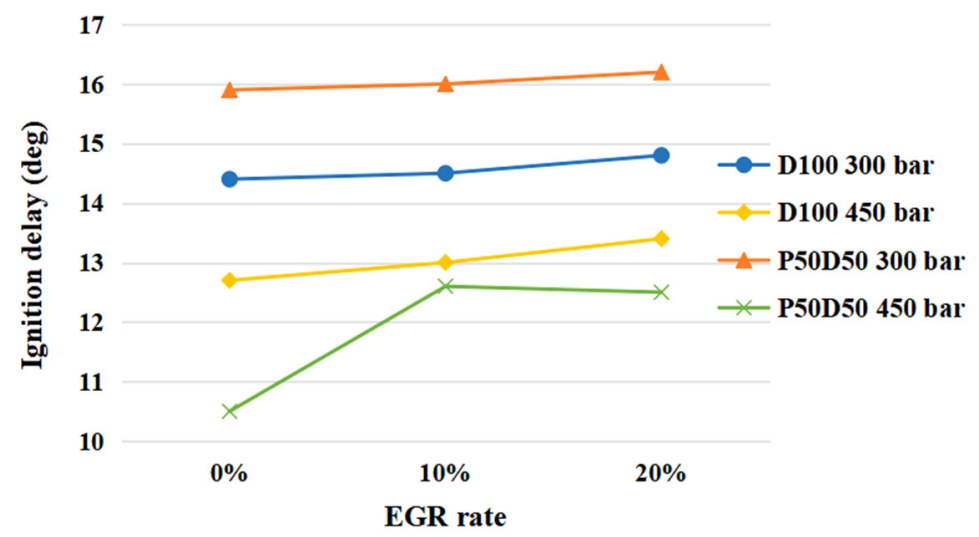

Figure 10. ID under different EGR rates at 300 and 450 bar. 


\subsubsection{Engine Performance}

Figures 11 and 12 show the effect of increasing the EGR rate on BSFC and BTE at high and low injection pressures. As shown, fuel consumption was generally higher at 450 bar injection pressure, and D100 exhibited a lower BSFC under all conditions due to its lower calorific value. While the injection pressure improved the atomization conditions, it also shortened the penetration length of the fuel, resulting in a slight lack of oxygen in the air, leading to more fuel consumption [23]. It may also be that the oxygen in palm oil improved the combustion quality, making up for the lack of calorific value to some extent. With the increase of EGR rate, the consumption of P50D50 was closer to that of D100. Under each injection condition, the BSFC of the two fuels increased with the increasing EGR rate, while BTE showed the opposite trend. The low oxygen concentration in the exhaust gas and the large specific heat capacity greatly reduced the peak combustion temperature in the cylinder, which may be the main reason for reducing its BTE $[35,37]$. In addition, according to the curve shown in Figure 12, EGR had a greater impact on BTE under a low injection pressure. At 300 bar injection pressure, a 20\% EGR rate reduced the efficiency of D100 and P50D50 by $2.3 \%$ and $3.4 \%$, respectively, but at 450 bar, it only reduced fuel efficiency by $1.9 \%$ and $0.9 \%$, respectively.

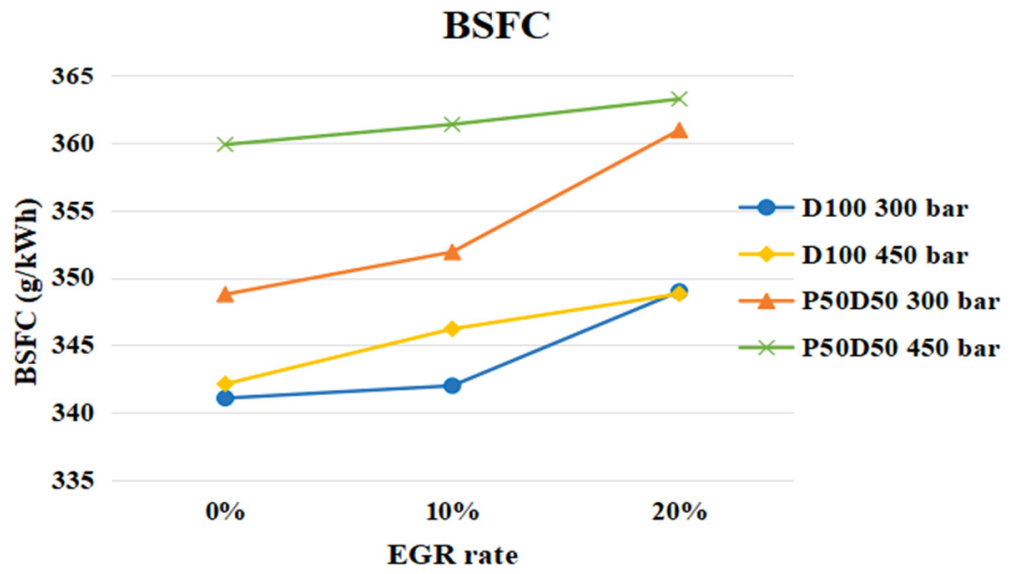

Figure 11. BSFC under different EGR rates at 300 and 450 bar.

\section{BTE}

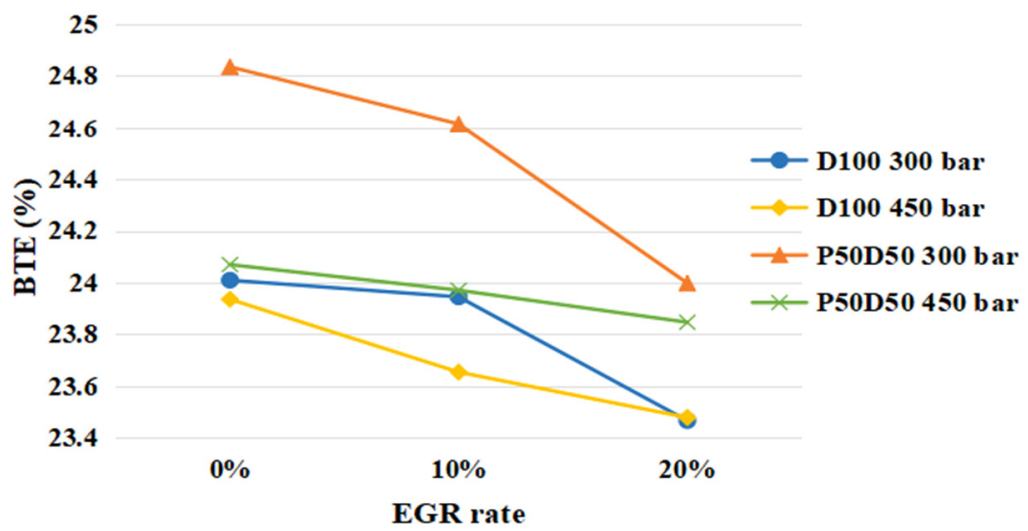

Figure 12. BTE under different EGR rates at 300 and 450 bar.

As shown in Figure 13, the EGT of all fuels showed a greater temperature rise with the introduction of EGR; especially, when a $20 \%$ EGR rate was introduced, the temperature reached the maximum. It is probably because EGR diluted the oxygen entering the cylinder and prolonged the ID period, thereby compressing the combustion time, which resulted in high EGT [38]. This performance is slightly different from that observed in other 
studies [35,39]. It was found that EGT decreased with the growth of EGR rate, mainly because EGR reduced the temperature in the cylinder. Furthermore, it can also be observed that P50D50 was more sensitive to EGR. At 450 bar and 20\% EGR rate, the EGT growth rate of P50D50 slowed down, while the EGT growth rate in other conditions was mostly linear.



Figure 13. EGT under different EGR rates at 300 and 450 bar.

\subsubsection{Emission Characteristics}

Figure 14 shows the effect of EGR rate on the NOx emissions of the two fuels at high and low pressures. EGR introduced exhaust gas into the cylinder, the oxygen content in the mixed gas was reduced, and the total heat capacity of the working gas increased, which helped to reduce the maximum temperature in the cylinder. EGR suppressed the high-temperature and oxygen-enrichment conditions for NOx forming, so the NOx emitted by the two fuels decreased with the increasing EGR rate [40,41]. Although the two fuels released similar volumes of NOx under the same conditions, it was also found that the NOx displacement of P50D50 was slightly higher than that of D100. This could be caused by the small amount of oxygen in palm oil.

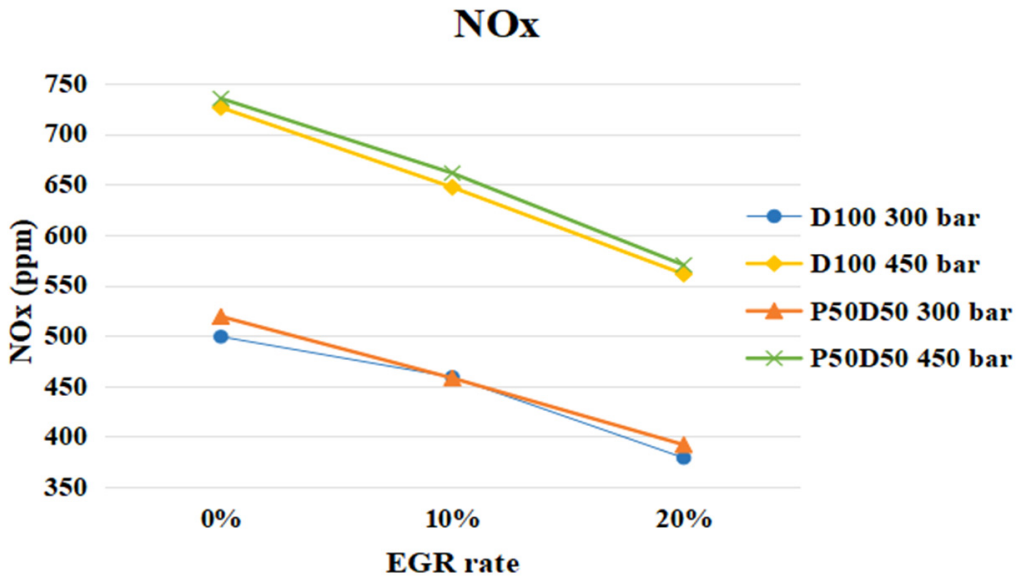

Figure 14. NOx emissions under different EGR rates at 300 and 450 bar.

Figure 15 plots the trend of smoke emissions with the EGR rate. Under different injection pressures, the smoke opacity displayed by D100 and P50D50 was positively correlated with the EGR rate. With the introduction of EGR, the oxygen entering the cylinder was reduced. A lower combustion temperature and the low oxygen concentration had an adverse effect on the oxidation of smoke, which accelerated the rate of formation of carbon nuclei from unsaturated soot precursors; therefore, more smoke was generated [34,35]. 
It can be noted that, under the same conditions, the smoke displacement produced by D100 was more sensitive to the EGR rate. At 300 and 450 bar injection pressures, 20\% EGR increased the smoke displacement of D100 by $69.2 \%$ and $56.3 \%$, respectively, while for P50D50, the increase was of $25 \%$ and $33.3 \%$. The oxygen atoms contained in palm oil increased the oxygen concentration of the fuel, which promoted the oxidation of smoke under the same injection conditions. As a result, the concentration of smoke produced by P50D50 showed lower variation. This could be due to the oxygen atoms in palm oil, which could better cope with changes in oxygen concentration in the intake air, showing lower fluctuations.

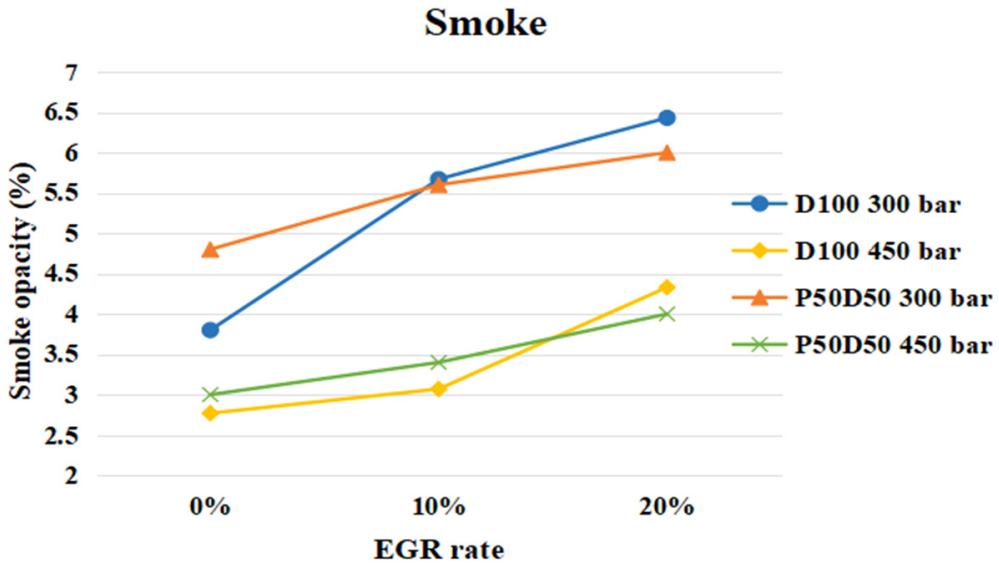

Figure 15. Smoke opacity under different EGR rates at 300 and 450 bar.

\section{Conclusions}

In this work, the effects of crude palm oil as a fuel mixture on engine combustion, engine performance, and NOx-smoke trade-off at incremental injection pressures and EGR rates were studied. The results are as follows:

- A high injection pressure helped to increase CPmax and HRRmax by up to $13.5 \%$, while shortening the ID. With the increase of injection pressure, BTE and EGT tended to increase first and then decreased, while BSFC behaved in the opposite way. High EGR rates had roughly the opposite effect of the injection pressure, which worsened the combustion results. BSFC and EGT increased monotonically with the increase of EGR rate, while BTE decreased accordingly. P50D50 embodies roughly the same fuel potential as diesel.

- A high injection pressure was beneficial to reduce smoke formation, but at the same time promoted NOx emissions. It is worth noting that under the injection pressure of 400 bar for P50D50, the generation of NOx and smoke was simultaneously suppressed. The advantage of a high EGR rate was only to decrease the in-cylinder temperature to reduce NOx emissions, which had a negative effect for smoke.

- The atomization problem caused by the high viscosity of crude palm oil could be alleviated by increasing the injection pressure. It was found that D100 was more sensitive at high EGR rates as shown by its emission characteristics. P50D50 behaved better at high injection pressures and high EGR rates, as shown by its low smoke emission at a $20 \%$ EGR rate.

Author Contributions: Methodology, G.W. and J.C.G.; investigation, G.W., J.C.G., M.S.K. and N.J.C.; data curation, G.W.; writing-original draft preparation, G.W.; writing—review and editing, J.C.G., M.S.K. and N.J.C.; funding acquisition, J.C.G. and N.J.C. All authors have read and agreed to the published version of the manuscript.

Funding: This research was supported by the Basic Science Research Program through the National Research Foundation of Korea (NRF) funded by the Ministry of Education (Project No. 2019R1I1A1A01057727 and No. 2021R1I1A3056655). 
Institutional Review Board Statement: Not applicable.

Informed Consent Statement: Not applicable.

Data Availability Statement: The data presented in this study are available on request from the corresponding author.

Conflicts of Interest: The authors declare no conflict of interest.

\section{References}

1. Zhang, Y.J.; Jiang, L.; Shi, W. Exploring the growth-adjusted energy-emission efficiency of transportation industry in China. Energy Econ. 2020, 90, 104873. [CrossRef]

2. Bilgen, S. Structure and environmental impact of global energy consumption. Renew. Sustain. Energy Rev. 2014, 38, 890-902. [CrossRef]

3. Mofijur, M.; Rasul, M.; Hyde, J. Recent developments on internal combustion engine performance and emissions fuelled with biodiesel-diesel-ethanol blends. Procedia Eng. 2015, 105, 658-664. [CrossRef]

4. Vassallo, A.; Beatrice, C.; di Blasio, G.; Belgiorno, G.; Avolio, G.; Pesce, F.C. The Key Role of Advanced, Flexible Fuel Injection Systems to Match the Future CO2 Targets in an Ultra-Light Mid-Size Diesel Engine. SAE Tech. Pap. 2018. [CrossRef]

5. di Blasio, G.; Beatrice, C.; Ianniello, R.; Pesce, F.C.; Vassallo, A.; Belgiorno, G.; Avolio, G. Balancing Hydraulic Flow and Fuel Injection Parameters for Low-Emission and High-Efficiency Automotive Diesel Engines. SAE Int. J. Adv. Curr. Prac. Mobil. 2020, 2, 638-652. [CrossRef]

6. Atmanli, A.; Ileri, E.; Yuksel, B.; Yilmaz, N. Extensive analyses of diesel-vegetable oil-n-butanol ternary blends in a diesel engine. Appl. Energy 2015, 145, 155-162. [CrossRef]

7. Ge, J.C.; Kim, H.Y.; Yoon, S.K.; Choi, N.J. Optimization of palm oil biodiesel blends and engine operating parameters to improve performance and PM morphology in a common rail direct injection diesel engine. Fuel 2020, 260, 116326. [CrossRef]

8. Ge, J.C.; Kim, H.Y.; Yoon, S.K.; Choi, N.J. Reducing volatile organic compound emissions from diesel engines using canola oil biodiesel fuel and blends. Fuel 2018, 218, 266-274. [CrossRef]

9. Knothe, G.; Razon, L.F. Biodiesel fuels. Prog. Energy Combust. Sci. 2017, 58, 36-59. [CrossRef]

10. Ge, J.C.; Wu, G.; Choi, N.J. Comparative study of pilot-main injection timings and diesel/ethanol binary blends on combustion, emission and microstructure of particles emitted from diesel engines. Fuel 2021, 122658. [CrossRef]

11. Yildiz, I.; Açıkkalp, E.; Caliskan, H.; Mori, K. Environmental pollution cost analyses of biodiesel and diesel fuels for a diesel engine. J. Environ. Manag. 2019, 243, 218-226. [CrossRef]

12. Tan, K.; Lee, K.; Mohamed, A.; Bhatia, S. Palm oil: Addressing issues and towards sustainable development. Renew. Sustain. Energy Rev. 2009, 13, 420-427. [CrossRef]

13. Yasin, M.H.M.; Mamat, R.; Najafi, G.; Ali, O.M.; Yusop, A.F.; Ali, M.H. Potentials of palm oil as new feedstock oil for a global alternative fuel: A review. Renew. Sustain. Energy Rev. 2017, 79, 1034-1049. [CrossRef]

14. Leevijit, T.; Prateepchaikul, G. Comparative performance and emissions of IDI-turbo automobile diesel engine operated using degummed, deacidified mixed crude palm oil-diesel blends. Fuel 2011, 90, 1487-1491. [CrossRef]

15. Mukherjee, I.; Sovacool, B.K. Palm oil-based biofuels and sustainability in southeast Asia: A review of Indonesia, Malaysia, and Thailand. Renew. Sustain. Energy Rev. 2014, 37, 1-12. [CrossRef]

16. Sankumgon, A.; Assawadithalerd, M.; Phasukarratchai, N.; Chollacoop, N.; Tongcumpou, C. Properties and performance of microemulsion fuel: Blending of jatropha oil, diesel, and ethanol-surfactant. Renew. Energy Focus 2018, 24, 28-32. [CrossRef]

17. Balat, M.; Balat, H. Progress in biodiesel processing. Appl. Energy 2010, 87, 1815-1835. [CrossRef]

18. Hazar, H.; Aydin, H. Performance and emission evaluation of a CI engine fueled with preheated raw rapeseed oil (RRO)-diesel blends. Appl. Energy 2010, 87, 786-790. [CrossRef]

19. Chauhan, B.S.; Kumar, N.; Du Jun, Y.; Lee, K.B. Performance and emission study of preheated Jatropha oil on medium capacity diesel engine. Energy 2010, 35, 2484-2492. [CrossRef]

20. Bari, S.; Lim, T.; Yu, C. Effects of preheating of crude palm oil (CPO) on injection system, performance and emission of a diesel engine. Renew. Energy 2002, 27, 339-351. [CrossRef]

21. Gebremariam, S.; Marchetti, J. Economics of biodiesel production. Energy Convers. Manag. 2018, 168, 74-84. [CrossRef]

22. Bohl, T.; Tian, G.; Smallbone, A.; Roskilly, A.P. Macroscopic spray characteristics of next-generation bio-derived diesel fuels in comparison to mineral diesel. Appl. Energy 2017, 186, 562-573. [CrossRef]

23. Jaichandar, S.; Annamalai, K. Combined impact of injection pressure and combustion chamber geometry on the performance of a biodiesel fueled diesel engine. Energy 2013, 55, 330-339. [CrossRef]

24. Saravanan, C.; Kiran, K.R.; Vikneswaran, M.; Rajakrishnamoorthy, P.; Yadav, S.P.R. Impact of fuel injection pressure on the engine characteristics of CRDI engine powered by pine oil biodiesel blend. Fuel 2020, 264, 116760. [CrossRef]

25. Hwang, J.; Qi, D.; Jung, Y.; Bae, C. Effect of injection parameters on the combustion and emission characteristics in a common-rail direct injection diesel engine fueled with waste cooking oil biodiesel. Renew. Energy 2014, 63, 9-17. [CrossRef]

26. Kannan, G.; Anand, R. Effect of injection pressure and injection timing on DI diesel engine fuelled with biodiesel from waste cooking oil. Biomass Bioenergy 2012, 46, 343-352. [CrossRef] 
27. Prabu, S.S.; Asokan, M.; Prathiba, S.; Ahmed, S.; Puthean, G. Effect of additives on performance, combustion and emission behavior of preheated palm oil/diesel blends in DI diesel engine. Renew. Energy 2018, 122, 196-205. [CrossRef]

28. Atmanl1, A.; Ileri, E.; Yüksel, B. Experimental investigation of engine performance and exhaust emissions of a diesel engine fueled with diesel-n-butanol-vegetable oil blends. Energy Convers. Manag. 2014, 81, 312-321. [CrossRef]

29. Kegl, B. Influence of biodiesel on engine combustion and emission characteristics. Appl. Energy 2011, 88, 1803-1812. [CrossRef]

30. Mahla, S.; Dhir, A.; Gill, K.J.; Cho, H.M.; Lim, H.C.; Chauhan, B.S. Influence of EGR on the simultaneous reduction of NOx-Smoke emissions trade-off under CNG-biodiesel dual fuel engine. Energy 2018, 152, 303-312. [CrossRef]

31. Gumus, M.; Sayin, C.; Canakci, M. The impact of fuel injection pressure on the exhaust emissions of a direct injection diesel engine fueled with biodiesel-diesel fuel blends. Fuel 2012, 95, 486-494. [CrossRef]

32. Kumar, S.; Dinesha, P.; Rosen, M.A. Effect of injection pressure on the combustion, performance and emission characteristics of a biodiesel engine with cerium oxide nanoparticle additive. Energy 2019, 185, 1163-1173. [CrossRef]

33. Channapattana, S.; Pawar, A.A.; Kamble, P.G. Effect of injection pressure on the performance and emission characteristics of VCR engine using honne biodiesel as a fuel. Mater. Today: Proc. 2015, 2, 1316-1325. [CrossRef]

34. Labecki, L.; Ganippa, L. Effects of injection parameters and EGR on combustion and emission characteristics of rapeseed oil and its blends in diesel engines. Fuel 2012, 98, 15-28. [CrossRef]

35. Bhowmick, P.; Jeevanantham, A.; Ashok, B.; Nanthagopal, K.; Perumal, D.A.; Karthickeyan, V.; Vora, K.; Jain, A. Effect of fuel injection strategies and EGR on biodiesel blend in a CRDI engine. Energy 2019, 181, 1094-1113. [CrossRef]

36. Can, Ö.; Öztürk, E.; Solmaz, H.; Aksoy, F.; Çinar, C.; Yücesu, H.S. Combined effects of soybean biodiesel fuel addition and EGR application on the combustion and exhaust emissions in a diesel engine. Appl. Therm. Eng. 2016, 95, 115-124. [CrossRef]

37. Ashok, B.; Nanthagopal, K.; Raj, R.T.K.; Bhasker, J.P.; Vignesh, D.S. Influence of injection timing and exhaust gas recirculation of a Calophyllum inophyllum methyl ester fuelled CI engine. Fuel Processing Technol. 2017, 167, 18-30. [CrossRef]

38. Zhou, X.; Qian, W.; Pan, M.; Huang, R.; Xu, L.; Yin, J. Potential of n-butanol/diesel blends for CI engines under post injection strategy and different EGR rates conditions. Energy Convers. Manag. 2020, 204, 112329. [CrossRef]

39. Singh, A.P.; Agarwal, A.K. Partially homogenous charge compression ignition engine development for low volatility fuels. Energy Fuels 2017, 31, 3164-3181. [CrossRef]

40. Yasin, M.H.M.; Mamat, R.; Yusop, A.F.; Paruka, P.; Yusaf, T.; Najafi, G. Effects of exhaust gas recirculation (EGR) on a diesel engine fuelled with palm-biodiesel. Energy Procedia 2015, 75, 30-36. [CrossRef]

41. Yoon, S.H.; Suh, H.K.; Lee, C.S. Effect of spray and EGR rate on the combustion and emission characteristics of biodiesel fuel in a compression ignition engine. Energy Fuels 2009, 23, 1486-1493. [CrossRef] 